\title{
Predictors of in-hospital mortality in critically ill patients with secondary and tertiary peritonitis
}

\author{
J Ballús Noguera, V Corral-Velez*, JC Lopez-Delgado, NL Betancur-Zambrano, M Rojas-Lora, N Lopez-Suñe, \\ XL Perez Fernandez, J Sabater Riera \\ From ESICM LIVES 2015 \\ Berlin, Germany. 3-7 October 2015
}

\section{Introduction}

Critically ill surgical patients remain at high risk of adverse outcomes as a result of intra-abdominal infection and its related prolonged length ICU of stay.

\section{Objectives}

The aim of our study was to identify the risk factors for in-hospital mortality of ICU patients suffering from complicated peritonitis, together with those factors associated with the development of tertiary peritonitis.

\section{Methods}

Prospective, observational study at our institution from 2011 to 2013. Baseline characteristics on admission, outcomes, microbiological results and antibiotics were used in our database for analysis.

\section{Results}

343 patients were included, 158 (46.1\%) with secondary and 185 (53.9\%) with tertiary peritonitis. $64.4 \%$ were male, age was $63.7 \pm 14.3$ years and APACHE was $19.4 \pm 7.8$. In-hospital mortality was $37 \%$. We showed a higher incidence of Candida spp. (Odds Ratio(OR):1.275;95\% Confidence Interval(CI):1.096-1.789; $P=0.016)$, Enterococcus faecium (OR:1.085;95\% CI:1.018-1.400;P=0.002) and Enterococcus spp. (OR:1.370;95\% CI:1.139-1.989; $P=0.047)$ in tertiary peritonitis. Higher rates in the use of cephalosporins was shown in secondary peritonitis (OR:3.51;95\% CI:1.139-10.817;P=0.035). Longer ICU stay (OR:1.019;95\% CI:1.004-1.034;P = 0.010), urgent surgery (OR:3.247;95\% CI:1.392-7.575;P = 0.006), total parenteral nutrition (OR:3.079;95\% CI:1.535-6.177; $\mathrm{P}=0.002)$ and stomach-duodenum as primary infection site (OR:4.818;95\% CI:1.429-16.247; P = 0.011) were factors associated with the development of tertiary peritonitis whereas suffering from localized peritonitis was protective for their development (OR:0.308;95\% CI:0.152-0.624; $\mathrm{P}=0.001$ ). Multivariate analysis showed that predictors for in-hospital mortality were age (OR:1.028;95\% CI:1.011-1.045;P = 0.001), arterial lactate (OR:1.088;95\% CI:1.043-1.136; p < 0.001) and APACHE on admission (OR:1.058;95\% CI:1.017-1.101;P = 0.005) and the need for Renal Replacement Therapy (OR:1.728;95\% CI:1.179-2.533;P = 0.005).

\section{Conclusions}

Complicated peritonitis remains a cause of higher mortality in ICU, with urgent surgery, Total Parenteral Nutrition needs and primary infection site of stomach-duodenum as the main factors associated with tertiary peritonitis. Worst APACHE II, higher arterial lactate, older age and Renal Replacement Therapy needs were predictors of in-hospital mortality in those patients.

Published: 1 October 2015

\section{References}

1. Riche FC, Dray X, Laisne MJ, et al: Factors associated with septic shock and mortality in generalized peritonitis: comparison between community-acquired and postoperative peritonitis. Crit Care 2009, 13(3) R99.

2. Montravers $P$, Chalfine $A$, Gauzit $R$, et al: Clinical and therapeutic features of nonpostoperative nosocomial intra-abdominal infections. Ann Surg 2004, 239(3):409-416

doi:10.1186/2197-425X-3-S1-A114

Cite this article as: Ballús Noguera et al:: Predictors of in-hospital mortality in critically ill patients with secondary and tertiary peritonitis. Intensive Care Medicine Experimental 2015 3(Suppl 1):A114. 